\title{
Evaluation of Education of Veterinarians in Animal
}

\section{Welfare Issues}

\author{
Stella Maris Huertas ${ }^{1}$, Déborah César ${ }^{2}$, José Piaggio ${ }^{1}$ and Andrés Gil ${ }^{1}$ \\ 1. Facultad de Veterinaria, Universidad de la Republica, Lasplaces 1550, CP 11600 Montevideo, Uruguay \\ 2. Instituto Plan Agropecuario, Bulevard Artigas 3802, CP 11700 Montevideo, Uruguay
}

\begin{abstract}
Education of veterinarians in animal welfare issues is important to improve the welfare and health of animals. A questionnaire to 250 veterinarians related to their knowledge on animal welfare issues has been carried out at the Veterinary School of the University of the Republic, Uruguay, during March-April 2012. The questions were related to the courses on animal welfare veterinarians received, their main field of work, the importance given to the information offered and the quality of the topics addressed. From the total of veterinarians surveyed, 45\% (112) answered the questionnaire. Of those who responded, $47 \%$ attended to three or more animal welfare courses, $18 \%$ assisted to two courses and $22 \%$ to one. The occupation of the $82 \%$ of respondents was with beef and dairy cattle (large animals) or in the meat industry equally. 10\% works with small animals (especially pets) and poultry (production and industry). The 95\% of respondents considered that animal welfare is very important for their daily work with animals. $65 \%$ reported that animal welfare concepts have high applicability in their job. $85 \%$ considered that animal welfare should be part of the veterinary curricula and $100 \%$ expressed their compliance to be present in other courses on the subject. These results emphasize the importance afforded by Uruguayan veterinarians to improve their knowledge on animal welfare and to continue including specific courses in the veterinary curricula.
\end{abstract}

Key words: Animal welfare, veterinarians, veterinary curricula, continuing education.

\section{Introduction}

The animal welfare is a complex multi-faceted issue including scientific, economic, religious, ethical and cultural dimensions, as recognized by the World Organization for Animal Health (OIE) as a priority in the 2001-2005 strategic plan and continued in subsequent plans up to now [1].

The Food and Agriculture Organization (FAO) recognizes that the welfare of humans and the welfare of animals are closely linked, and states that animal welfare practices lead to benefits for both people and their animals [2].

Thus, animal welfare is becoming ever more important in the world, not only by the requirements of consumers [3] but also by the increasing awareness perceived by all the actors of the animal products

Corresponding author: Stella Maris Huertas, professor, research fields: animal health, animal welfare and meat quality. E-mail: stellamaris32@gmail.com. supply chains and the government in general.

Americas, a large and diverse continent, is designed to be the world supplier of animal food products due to its production and export volume [4]. This implies that a large number of animals are growing in different production systems, are transported by different ways and are slaughtered to produce meat, all of which involve a large number of stakeholders such as producers, stockpersons, truck drivers, industry employees, practitioners, etc., working in many cases without adequate knowledge to move animals [5, 6].

However, in Latin American countries, a large variation is perceived in breeding conditions, transport and slaughter of farm animals, perhaps due to a combination of geographic, climatic and cultural characteristics of each country. It may be also due to the different animal species used for meat (cattle, horses, sheep, pigs, goats, camels, rabbits, guinea pigs, 
fish, etc.), as well as each particular production systems and market characteristics [7].

An improper handling of animals prior to slaughter, such as very long journeys of transport and too many animals per vehicle [8-10], can cause injuries and suffering in the animals, resulting in bruise at the carcasses and thus great economic losses due to condemnations of the final product [11-13].

In this sequence, the role of the veterinarian is crucial in spreading knowledge, increasing awareness, training all the chain's actors and thus contributing to obtain a high quality final product that meets the health and animal welfare of international requirements [14].

Several initiatives in this direction have been carried out in Latin America, including research, training and legislation with encouraging results that trained staff in the implementation of best management practices (BMP) before slaughter reduces the incidence of bruising in cattle and pigs [15, $16]$.

In the last years, in many Latin American countries, the awareness of animal welfare has been increasing among the stakeholders involved in the animal food products chain, such as producers, farmers, stockpersons, markets and slaughter houses, practitioners and truck drivers. The BMP information has been transmitted through courses and seminars [15, 17].

All the stakeholders play an important role in changing perceptions of animal welfare by increasing public awareness and promoting communication and cooperation [18].

In Uruguay, studies conducted by the Veterinary Faculty of University of the Republic, showed that the most devices to force cattle to move were sticks, electric prods and poorly trained dogs at $62 \%, 21 \%$ and $32 \%$, respectively, all of which could cause injury to the animals [19].

Other studies also showed associations among different factors affecting the animals at pre-slaughter stages, such as the distance from the farms to slaughter plants, the state of routes travelled, sharp devices used to move the animals and the consequent presence of bruises at the carcasses [11].

There is no data in the country or in the region about the information on animal welfare received by the veterinarians. The main objective of this work was to collect information about the perception of practitioners on training programs and their willingness to continue receiving information and training on animal welfare.

\section{Materials and Methods}

A brief questionnaire was sent by email to 250 veterinarians, whose data were in the database of the Veterinary Faculty of the University of the Republic of Uruguay, at the Continuing Education Program which has been taken as a course related to animal welfare issues. The details of questions are shown in Table 1.

Descriptive analysis of the data was performed with a statistical package Intercooled Stata 11.2 (2009) in order to obtain the frequencies of each variable considered [20].

\section{Results and Discussion}

The survey was carried out during February-March 2012. From 250 veterinarians surveyed, 112 (45\%) answered the questionnaire. Fig. 1 shows that almost half of the veterinarians attended to more than three animal welfare courses in the last time in the country. Fig. 2 shows an interesting breaking point since 2010 with an increasing tendency of animal welfare courses attended by the veterinarians along the last years. These actions may be due to the setting up of the OIE collaborating centre on animal welfare in May of 2009 [21].

The $82 \%$ of respondents worked with large animals (mainly beef cattle) and in meat industry equally. This characteristic is typical in Uruguay, a small South American country, with approximately 3 million people 
Table 1 Brief questionnaire sent by email to 250 Uruguayan veterinarians.

Dear Colleague please fill in the blanks:

1. How many courses animal welfare/good management practices have you performed?

\begin{tabular}{llll}
\hline One & Two & Three & More than three \\
\hline
\end{tabular}

2. Do you remember the years?

3. In what area do you work?

\begin{tabular}{llll}
\hline Large animals (cattle, sheep, horses) & Birds & Small (company) & $\begin{array}{l}\text { Food industry (slaughter house, } \\
\text { meat industry) }\end{array}$
\end{tabular} Other

4. What importance do you assigned to animal welfare/good management practices for technical performance of the veterinarian or handlers?

High
5. Was the information received in the courses on animal welfare/good management practices useful for your daily work with
animals?

$\begin{array}{lll}\text { Little } & \text { Much } & \text { Nothing }\end{array}$

6. Although animal welfare was not part to the Curricula when you took the veterinary courses, do you believe that it would be necessary in the current vet training?

Yes No

7. Are you willing to attend an activity relating to this subject again?

Yes No

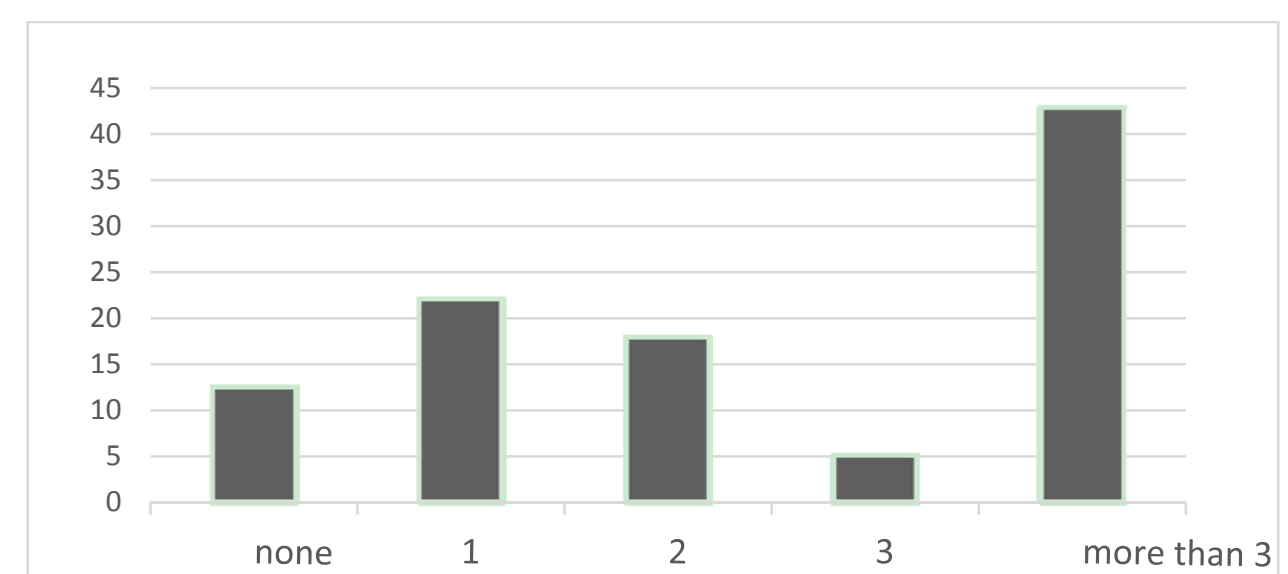

Fig. 1 Numbers of courses attended by each Uruguayan veterinarians according to their answers in February-March 2012.

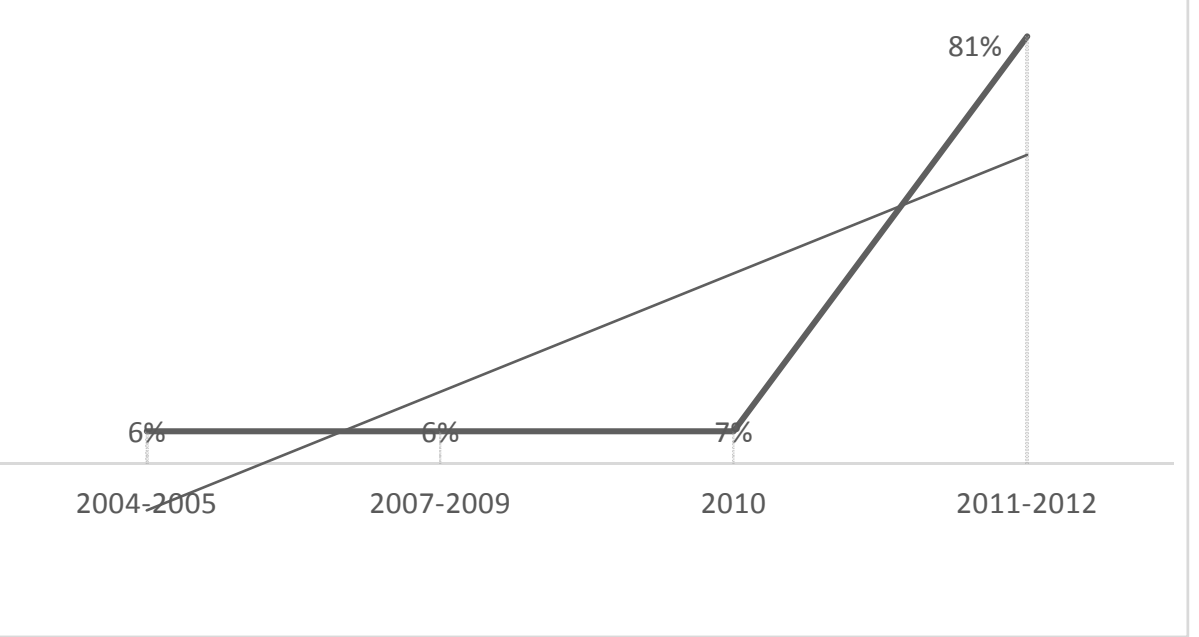

Fig. 2 Evolution of animal welfare courses attended by Uruguayan veterinarians along the last years. 
and almost 12 million cattle head of European breeds for beef production and exporting of high quality meat to the world [14]. So it is crucial that veterinarians working with production animals should be involved with the "general principles for the welfare of animals in livestock production systems", which was supported and adopted by the OIE in a guide to develop animal welfare standards [21]. The $10 \%$ of the veterinarians answered that they worked with small animals (especially pets) and poultry (production and industry) and the rest did not answer this question.

The 95\% of respondents considered that animal welfare concept is very important for their daily work with animals and also in relation to the applicability in their daily work. 65\% reported that animal welfare has high relevance in their jobs. It is remarkable that veterinarians surveyed belong to the database of the Continuing Education Program, so perhaps they are better predisposed to attend those kinds of courses.

When asked whether they considered that the animal welfare should be part of the veterinary curricula, 85\% considered that it should be part and all of them have expressed their compliance to be present in other courses on the subject.

These outcomes clearly showed that the OIE collaborating centre on animal welfare and livestock production systems, a consortium among Chile, Uruguay and Mexico, is working closely with the OIE official delegates and the Uruguayan animal welfare Focal Point of the Veterinary Services, increasing the awareness on animal welfare and promoting the training of all stakeholders including veterinarians [17, 21].

\section{Conclusions}

These results show clearly the importance of the transfer and exchange of knowledge among all the stakeholders to improve animal welfare in the country and in the region. And it contributes to improve food quality and safety as well as operator security and productivity of the sector.
It is necessary to continue spreading the animal welfare to all professionals, also including those who work in other areas.

Dissemination of knowledge and training of animal welfare issues among veterinarians are the key to achieve substantial improvements as drivers of animal welfare policy in the Americas.

Definitely, training of veterinarians is a key element to improve animal welfare through a big change in mind and attitude towards animals.

\section{Acknowledgments}

The authors thank Dr. Teresita Alonso of the Continuing Education Program at the Facultad de Veterinaria de la Universidad de la República for her cooperation.

\section{References}

[1] World Organization for Animal Health (OIE). 2014. “OIE’s Achievements in Animal Welfare.” Accessed April 18, 2015. http://www.oie.int/en/animal-welfare/animal-welfare-key -themes/.

[2] Food and Agriculture Organization (FAO). 2008. "Capacity Building to Implement Good Animal Welfare Practices.” In Proceedings of FAO Expert Meeting, 8.

[3] European Commission. 2007. "Attitudes of EU Citizens towards Animal Welfare.” Special Eurobarometer 270/ Wave 66.1-TNS Opinion \& Social. Accessed April 18, 2015. http://ec.europa.eu/public_opinion/archives/ebs/ebs _270_en.pdf.

[4] Food and Agriculture Organization (FAO). 2009. "The State of Food and Agriculture 2009: Livestock in the Balance.” Accessed May 12, 2015. http://www.fao.org/docrep/012/i0680e/i0680e00.htm.

[5] Huertas-Canén, S. M. 2012. “Good Management Practices during Loading and Transport to the Slaughter House.” In Animal Welfare, Productivity and Quality of Meat, 2nd ed.. Mexico: Elsevier, 139-54. (in Spanish)

[6] Huertas-Canén, S. M., Mota-Rojas, D., Zermeño-Acosta, M., and Borderas-Tordesillas, F. 2012. "Assessment Methods of Driving Animals for Slaughter.” In Animal Welfare, Productivity and Quality of Meat, 2nd ed.. Mexico: Elsevier, 91-114. (in Spanish)

[7] Gallo, C. 2012. "Animal Welfare and Meat Quality in Latin America.” In Animal Welfare, Productivity and Quality of Meat, 2nd ed.. Mexico: Elsevier, 3-11. (in 
Spanish)

[8] Gallo, C. 2008. "Using Scientific Evidence to Inform Public Policy on the Long Distance Transportation of Animals in South America.” Veterinaria Italiana 44 (1): $113-20$.

[9] Gallo, C., Warriss, P., Knowles, T., Negrón, R., Valdés, A., and Mencarini, I. 2005. "Stocking Densities Used for the Commercial Transport of Cattle to Slaughter House in Chile.” Arch. Med. Vet. 37 (2): 155-9.

[10] Paranhos da Costa, M., Huertas, S., Strappini, A., and Gallo, C. 2014. "Assessment Methods of Driving Animals for Slaughter." In Livestock Handling and Transport, 4th ed., edited by Grandin, T. Wallingford, UK: CAB International, 174-92.

[11] Huertas, S., Gil, A., Piaggio, J., and van Eerdenburg, F. 2010. "Transportation of Beef Cattle to Slaughter Houses and Its Relation to Animal Welfare and Meat Quality in an Extensive Production System.” Animal Welfare 19: 281-5.

[12] National Institute for Agricultural Research (INIA) and National Meat Institute (INAC). 2009. "Second Beef Quality Audit of Uruguay 2007-2008.” Accessed April 18 ,

2015. www.inac.gub.uy/innovaportal/file/3001/1/auditoria_bovi na_2009_web.pdf. (in Spanish)

[13] National Institute for Agricultural Research (INIA), National Meat Institute (INAC) and Colorado State University. 2003. “Beef Quality Audit 2003.” Accessed April 18, 2015. www.inac.gub.uy/innovaportal/file/3015/1/cartilla_vacun a_2003_vers_final.pdf. (in Spanish)

[14] Huertas, S. 2012. "Continuing Training and Education of Graduate Veterinarians in Animal Welfare.” In
Proceeding of the Third OIE Global Conference on Animal Welfare.

[15] César, D., and Huertas, S. 2007. “The Diffusion and Training Experience in Animal Welfare and Good Management Practices at the Beef Cattle Chain in Uruguay." In Proceeding of the Regional Seminar on Animal Welfare: Strategies for Dissemination of Good Animal Husbandry, 85-93. (in Spanish)

[16] Paranhos da Costa, M., Huertas, S., Gallo, C., and Dalla-Costa, O. 2012. "Strategies to Promote Farm Animal Welfare in Latin America and Their Effects on Carcass and Meat Quality Traits.” Meat Science 92 (3): 221-6.

[17] Galindo, F., Huertas, S., and Gallo, C. 2014. "OIE Strategy for the Teaching of Animal Welfare in the Americas.” In Animal Welfare and Veterinary Education in Latin America. Mexico: Guadalajara University, 63-70. (in Spanish)

[18] Huertas, S., Gallo, C., and Galindo, F. 2014. "Drivers of Animal Welfare Policy in the Americas.” Rev. Sci. Tech. 33 (1): 67-76.

[19] Gil, A., and Huertas, S. 2007. "Dissemination of Animal Welfare Principles and Good Management Practices along the Whole Meat Chain.” In Proceeding of the Regional Seminar on Animal Welfare: Strategies for Dissemination of Good Animal Husbandry, 109-16. (in Spanish)

[20] STATA. 2009. Data Analysis and Statistical Software 2009. USA: StataCorpm LP.

[21] World Organization for Animal Health (OIE). 2009. "Collaborating Centre on Animal Welfare and Livestock Production Systems.” Accessed April 18, 2015. http://www.oie.int/our-scientific-expertise/collaborating-c entres/list-of-centres. 